\title{
Analysis of the Blasting Compaction on Gravel Soil
}

\author{
Qingwen Li, ${ }^{1,2}$ Yuan Li, ${ }^{1}$ Gautam Dasgupta, ${ }^{2}$ Dongping Song, ${ }^{2}$ Lan Qiao, ${ }^{1}$ \\ Liping Wang, ${ }^{3}$ and Jianghui Dong ${ }^{4}$ \\ ${ }^{1}$ The Department of Civil and Environmental Engineering, University of Science and Technology Beijing, Beijing 100083, China \\ ${ }^{2}$ The Department of Civil Engineering and Engineering Mechanics, Columbia University, New York, NY 10027, USA \\ ${ }^{3}$ Sansom Institute for Health Research, School of Pharmacy and Medical Sciences, University of South Australia, \\ Adelaide, SA 5001, Australia \\ ${ }^{4}$ School of Natural and Built Environments, University of South Australia, Adelaide, SA 5095, Australia
}

Correspondence should be addressed to Yuan Li; sbfqp@126.com

Received 28 August 2014; Accepted 20 September 2014

Academic Editor: Tifeng Jiao

Copyright (C) 2015 Qingwen Li et al. This is an open access article distributed under the Creative Commons Attribution License, which permits unrestricted use, distribution, and reproduction in any medium, provided the original work is properly cited.

\begin{abstract}
The settlement control is critical for the safety of road based on high filled embankment. The traditional construction methods have the characteristic with less soil thickness compacted at a time. There are many advantages to compact the gravel soil with blasting. The cavity in soil is formed by blasting and its fillings to form a composite foundation for the embankment. The field data show this composite foundation can meet the requirement of loading and settlement control with less construction time. In geotechnical blasting, the high temperature due to blasting will swell the material around, so its worthy to do the coupled analysis with thermal mechanics (TM) and blasting compaction in the high filled embankment. In this paper, a 3D model is built with FLAC3D to simulate a single hole to predict the range and degree of thermal propagation. Then, the thermal strains got from the model are used to estimate the displacement of surrounding soil to predict the degree of compaction and optimize the distribution of blast holes in plan.
\end{abstract}

\section{Introduction}

For road constructed in mountain area, embankment is one of the most commonly used construction methods, especially the high filled embankment. However, the high filled embankment has the characteristics of higher filling height and larger filling cross-sectional area which means larger accumulated settlement and longer settlement period than normal embankment. The settlement of high filled embankment plays a vital role in road quality and driving safety and construction and operating economy [1]. These make the high filled embankment highly desirable if it possesses sufficient loading capacity and slope stability. Moreover, if the settlement can be mitigated in advance fast and stably, the construction period can be significantly shortened. Other obvious advantages include reduced engineering costs, land conservation, and better social economy. So far, the settlement of high filled embankment has been studied by many scholars using different treatment methods, such as drainage consolidation method $[2,3]$, vacuum consolidation method [4], dynamic compaction [5-7], and shock compaction method $[8,9]$. However, each method mentioned above uses less soil thickness compacted at a time and long construction cycle time, especially for the high filled embankment whose construction cycle time is usually 1 to 2 years, which delays the construction progress seriously. Many researchers tried to adopt the prefabricated vertical drains method [10-12] to shorten the construction period of embankment, but this method is only effective for embankment based on soft soil. With the development of advanced blasting technique, explosive compaction method could be used to improve the foundation and embankment. In this paper, the charges in the vertical arrangement blast holes were used to generate high pressure gas and the shock wave in order to compact the surrounding soil. Then, the blasting chambers were filled with gravel or other materials to form a shaft which combine with the compacted surrounding soil to form a composite embankment. This kind of composite foundation 
can effectively improve the bearing capacity and stabilize roadbed settlement situation. Simultaneously, the hole can be drilled to the bottom of the embankment to achieve the high filled embankment compacted at a time.

With the development of computer technology, finite element method (FEM) has been adopted by many scholars to analyze the settlement of embankment. Indraratna et al. used the numerical modeling to simulate the consolidation by vertical drain beneath a circular embankment [13]; Abusharar et al. adopted the finite element modeling to analyze the consolidation behavior of multicolumn supported road embankment [14]; Yildiz simulated the embankments on PVD improved soft clays with numerical method [15]; $\mathrm{Li}$ et al. used finite element to analyze the dynamic compaction in soft foundation [16]; Yuan et al. analyzed the 3D ground deformation by using a newly developed stereo-PIV technique [17]; therefore, it is highly feasible to use different constitutive models embedded in FEM software to analyze the settlement of embankment.

In blasting, the temperature at the center of hole can reach as high as $3000^{\circ} \mathrm{C}$, so the temperature influence on surrounding soil cannot be ignored. The temperature is related to the gas pressure. In this paper, based on the analysis of the change of blasting pressure, the volume expansion of the blast hole, the development of fracture in soil, and the motion of blasting gas were analyzed in the accurate mathematical model. The shape of blasting load changing with time was established. Finally, the field monitored data of blasting compaction were used to compare with the results of $3 \mathrm{D}$ model considering the TM coupled effect and verified the usefulness of 3D model to predict the settlement of high filled embankment.

\section{Process of Blasting Loading}

The dynamic loading due to blasting is a complex process. The blasting load can make the volume of blast hole enlarge and the fracture of soil expanded. The gas pressure and dynamic load will be reduced with volume enlargement. Finally, the explosive gas rapidly overflows and the applied force decays to zero when fractures developed to connect together.

At the beginning of blasting, the dynamic load will increase with time until it reaches the peak intensity of blasting when the detonation gas wave propagates to the bottom of blast hole. Many researches showed that the initial peak blasting load was related to the detonation wave pressure. According to the Chapman-Jouguet model by Henrych [18] for decoupled charges, the initial explosion pressure was also related to the ratio of the blast hole diameter and the charge diameter. The formula is

$$
P_{1}=\frac{\rho_{0} V_{D}}{2(\gamma+1)}\left(\frac{a}{b}\right)^{2 \gamma}
$$

where $V_{D}$ is the velocity of detonating gas, $\gamma$ is specific heat ratio of detonating gas, $a$ is the charge diameter, and $b$ is the blast hole diameter.

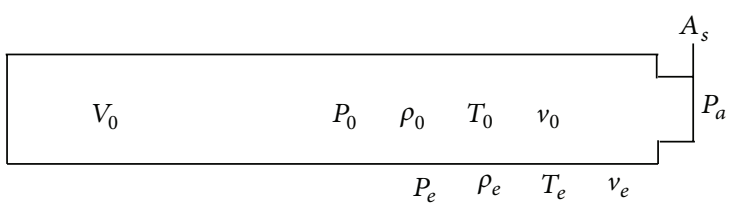

FIGURE 1: Equivalent structure of blasting.

Under this condition, the rising time of load can be shown as

$$
t_{1}=\frac{L}{V_{D}}
$$

where $L$ is the length of blast hole.

Before the fillings were erupted, according to gas law, gas pressure with volume change in detonation cavity could be shown as [19]

$$
P_{2}=A\left(1-\frac{\omega}{R_{1} V}\right) e^{-R_{1} V}+B\left(1-\frac{\omega}{R_{2} V}\right) e^{-R_{2} V}+\frac{\omega E_{0}}{(V)} .
$$

Considering the volume change, we can get

$$
\begin{aligned}
P_{2}(t)= & A\left(1-\frac{\omega}{R_{1}\left(V_{0}+\Delta V(t)\right)}\right) e^{-R_{1}\left(V_{0}+\Delta V(t)\right)} \\
& +B\left(1-\frac{\omega}{R_{2}\left(V_{0}+\Delta V(t)\right)}\right) e^{-R_{2}\left(V_{0}+\Delta V(t)\right)} \\
& +\frac{\omega E_{0}}{\left(V_{0}+\Delta V(t)\right)},
\end{aligned}
$$

where $V_{0}$ is the initial volume of blast hole, all of $A, B, R_{1}$, $R_{2}$, and $\omega$ are explosive material parameters, and $E_{0}$ is initial energy of explosive.

After the fillings were ejected or the blasting without fillings, the explosion gas erupted out from the blast hole quickly which induces the pressure lower. According to gas dynamics theory, the blast hole in this period can be treated as a bottle structure which is shown in Figure 1.

In Figure $1, V_{0}, P_{0}, \rho_{0}, T_{0}$, and $v_{0}$ are the initial volume, initial pressure, initial density, initial temperature, and initial velocity, respectively. $P_{e}, \rho_{e}, T_{e}$, and $v_{e}$ are the pressure, density, temperature, and velocity at the section of exit, respectively.

Then, the First Law of Thermodynamics was used with taking advantage of adiabatic process and gas flow in blast holes:

$$
\begin{aligned}
P_{3}(t+d t) & \\
& =P_{e}(t)\left(1-\frac{A_{s}}{V}\left(\frac{2}{\gamma+1}\right)^{(\gamma+1) / 2(\gamma-1)} \frac{\sqrt{\gamma P_{0} \rho_{0}}}{\rho_{e}(t)} d t\right)^{\gamma} .
\end{aligned}
$$

Based on these analysis steps of blasting process, the specific blasting loading curve was created and shown in Figure 2. 


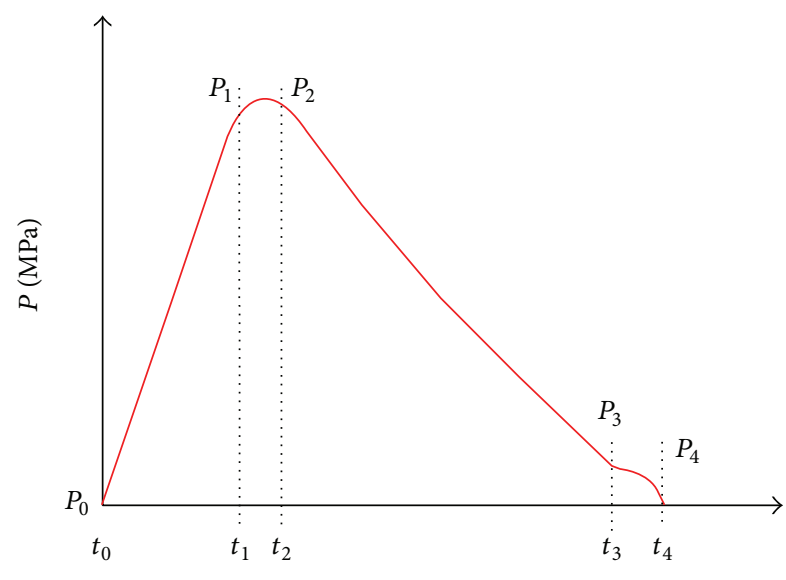

FIgURE 2: Blasting loading shape.

\section{TM Coupled Constitutive Model}

3.1. Elastic Model. According to the Fourier law, the Thermal Conduction Equation is

$$
\frac{\partial T}{\partial t}=\frac{1}{C_{p} \rho}\left(k_{x} \frac{\partial^{2} T}{\partial x^{2}}+k_{y} \frac{\partial^{2} T}{\partial y^{2}}\right),
$$

where $T$ is the temperature, $C_{p}$ is the specific heat, $\rho$ is density, and $k_{x}$ and $k_{y}$ are thermal conductivity in $x$ and $y$ direction, respectively.

For deformable materials, the stress increment caused by the temperature increasing is

$$
\Delta \sigma_{i j}=-\delta_{i j} K \alpha^{T} \Delta T
$$

where $\Delta \sigma_{i j}$ is stress increment, $K$ is the bulk modulus, $\alpha^{T}$ is thermal expansion coefficient, and $\Delta T$ is the temperature increment.

According to the generalized Hooke's law

$$
\sigma_{i j}=2 G \varepsilon_{i j}+3 \lambda \varepsilon_{k k} \delta_{i j}
$$

where $\sigma_{i j}$ is the stress, $\varepsilon_{i j}$ is the total strain, $\varepsilon_{k k}$ is the normal strain, $\lambda=E v /(1+\nu)(1-2 v), G=E / 2(1+\nu)$, and $\delta_{i j}$ is Kronecker's delta; when $i=j$, the value is 1 , and when $i \neq j$, its value is 0 .

Based on Hooke's law and considering the change of temperature and pore water pressure, Lewis and Schrefler proposed the effective stress $\sigma_{i j}^{\prime}[20]$

$$
\sigma_{i j}^{\prime}=2 G\left(\varepsilon_{i j}+\delta_{i j} \frac{\nu}{1-2 \nu} \varepsilon_{k k}\right)-K \alpha^{T} \Delta T \delta_{i j}
$$

where $\delta_{i j}$ is Kronecker's delta; when $i=j$, the value is 1 ; when $i \neq j$, its value is $0 . K=2 G(1+\nu) / 3(1-2 \nu)$ is bulk modulus under the drained condition. $\alpha^{T}$ is volume thermal expansion coefficient with water saturation degree and porosity [21]. It can be expressed as

$$
\alpha^{T}=\alpha_{\text {dry }}^{T}\left[1+4 \frac{\phi S_{w} \rho_{w}}{(1-\phi) \rho_{s}}\right],
$$

where $\alpha_{\mathrm{dry}}^{T}$ is the thermal expansion coefficient under the dry condition, $\phi$ is the porosity of the host rock, $S_{w}$ is the water saturation degree, and $\rho_{w}$ and $\rho_{s}$ are the density of the water and solid matrix.

3.2. Plasticity Model. First Invariant of Stress Tensor $I_{1}$ was considered in the Drucker-Prager model, which was based on the Generalized Mises Condition. Therefore, the yield condition could be expressed as

$$
F=\alpha I_{1}+\sqrt{J_{2}}-k=0
$$

where $I_{1}$ is the First Invariant of Stress Tensor, $J_{2}$ is the Second Invariant of Stress Tensor, and $\alpha$ and $k$ are the functions of cohesion $c$ and internal friction angle $\phi$ of geotechnical materials, which could be shown as

$$
\begin{gathered}
\alpha=\frac{2 \sqrt{3} \sin \phi}{2 \sqrt{3} \pi\left(9-\sin ^{2} \phi\right)}, \\
k=\frac{6 \sqrt{3} c_{1} \sin \phi}{2 \sqrt{3} \pi\left(9-\sin ^{2} \phi\right)} .
\end{gathered}
$$

3.3. Solid Mass Balance. The solid mass balance was given as [22]

$$
\frac{D_{s} \rho^{d}}{D t}+\rho^{d} \nabla \vec{v}^{s}=0,
$$

where $D_{s}() / D t$ is the material derivative with respect to the solid particles which move with a velocity vector $\vec{v}^{s}(\mathrm{~m} / \mathrm{s})$, $\nabla()$ is the divergence operator, and $\rho^{d}$ is the dry density of material where $\rho^{d}$ is the dry density of the medium which is equal to $\rho^{d}=\rho^{s}(1-\phi)$, where $\rho^{s}$ is the density of the solid particles $\left(\mathrm{kg} / \mathrm{m}^{3}\right)$. If the coefficient of the thermal expansion of the solid particles $\left(1 /{ }^{\circ} \mathrm{C}\right), C_{T}^{s}$, is considered and the mechanical compressibility of the particles is disregarded, then it becomes

$$
\frac{D_{s} \phi}{D t}=(1-\phi)\left[\nabla \vec{v}-C_{T}^{s} \frac{D_{s} T}{D t}\right],
$$

where $T$ is the temperature $\left({ }^{\circ} \mathrm{C}\right)$.

3.4. Temperature Change. According to the isentropic gas law, the temperature change had the relationship with the gas pressure; the formula can be expressed by well-known formula,

$$
\frac{P(t)}{P_{0}}=\left(\frac{T(t)}{T_{0}}\right)^{\gamma}
$$

where $P(t)$ is the gas pressure at any time, $P_{0}$ is the maximum gas pressure, $T(t)$ is the temperature of any time, $T_{0}$ is the maximum temperature, in this geotechnical blasting, $T_{0}=$ $3000^{\circ} \mathrm{C}$, and $\gamma$ is the specific heat ratio of the gas. 


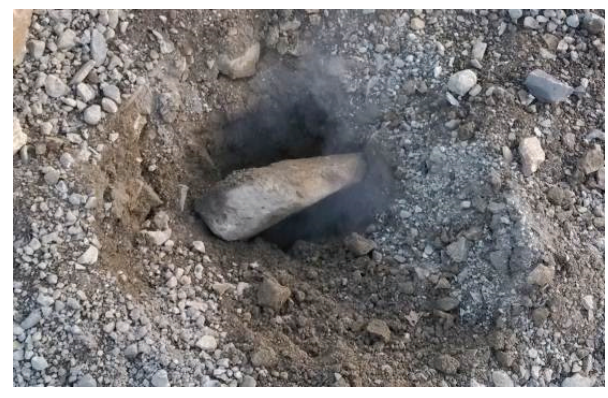

FIGURE 3: Blast cavity after blasting.

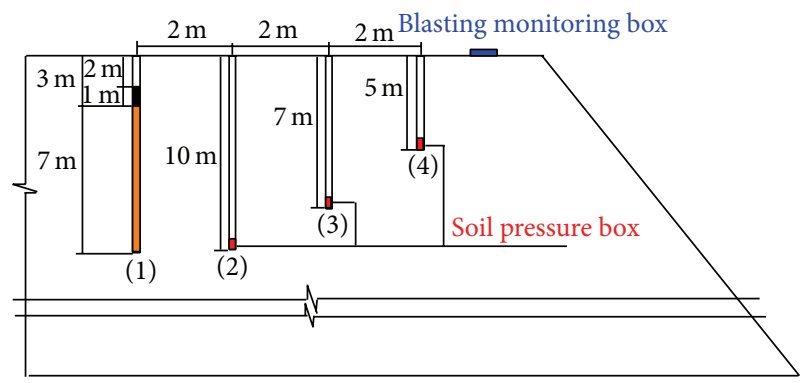

FIgURE 4: Arrangement of instruments and blast holes.

TABLe 1: Parameters of explosive.

\begin{tabular}{lccc}
\hline $\begin{array}{l}\text { Charge diameter } \\
(\mathrm{mm})\end{array}$ & Weight $(\mathrm{g})$ & Density $\left(\mathrm{g} / \mathrm{cm}^{3}\right)$ & $\begin{array}{c}\text { Blasting } \\
\text { velocity }(\mathrm{m} / \mathrm{s})\end{array}$ \\
\hline 32 & $200 \pm 10$ & $0.95 \sim 1.3$ & 3200 \\
\hline
\end{tabular}

\section{Project Study}

4.1. Project Background. In this paper, Jinxing Road K14+672-K14+750 in Chengde City, Hebei Province, was chosen as project background, whose maximum filled height was $60 \mathrm{~m}$, the length was $14 \mathrm{~m}$, and slope gradient ratio was $1: 1.5$. The filled materials were cutting gravel and soil from adjacent road sections (Figure 3 ).

4.2. Field Test. In order to obtain the soil properties under blasting, many field tests were carried on. In the tests, the depth of blast hole was $10 \mathrm{~m}$, the diameter was $110 \mathrm{~mm}$, and charges were 4 volumes together by number 2 emulsion explosives with the $7 \mathrm{~m}$ length. The length of fillings was $1 \mathrm{~m}$. The basic parameters of explosive are shown in Table 1.

In field, three series of soil pressure boxes were set on the distance from the blasting point $2 \mathrm{~m}, 4 \mathrm{~m}$, and $6 \mathrm{~m}$, respectively, to monitor the dynamic pressure, and a vibration monitoring box was used to monitor the vibration velocity at $7 \mathrm{~m}$. The arrangement details were shown in Figure 4.

4.3. Constitutive Parameters. In interest of analysis of the situation of blasting compaction, the constitutive parameters shown in Table 3 were obtained from lab tests. The soil compaction tests and moisture content and density tests are shown in Figures 5 and 6 and Tables 2 and 4.
TABLe 2: Pressure and compression modulus.

\begin{tabular}{lccc}
\hline Pressure $(\mathrm{kPa})$ & Porosity & $\begin{array}{c}\text { Compression } \\
\text { coefficient } \\
\left(\mathrm{Mpa}^{-1}\right)\end{array}$ & $\begin{array}{c}\text { Compression } \\
\text { modulus } \\
(\mathrm{MPa})\end{array}$ \\
\hline 0 & 0.369 & & \\
200 & 0.346 & 0.11 & 12.11 \\
400 & 0.337 & 0.05 & 30.41 \\
600 & 0.331 & 0.03 & 45.62 \\
800 & 0.325 & 0.03 & 45.62 \\
1000 & 0.319 & 0.03 & 45.62 \\
1200 & 0.314 & 0.03 & 54.74 \\
1600 & 0.305 & 0.02 & 60.83 \\
2000 & 0.297 & 0.02 & 60.83 \\
2400 & 0.290 & 0.02 & 78.20 \\
\hline
\end{tabular}

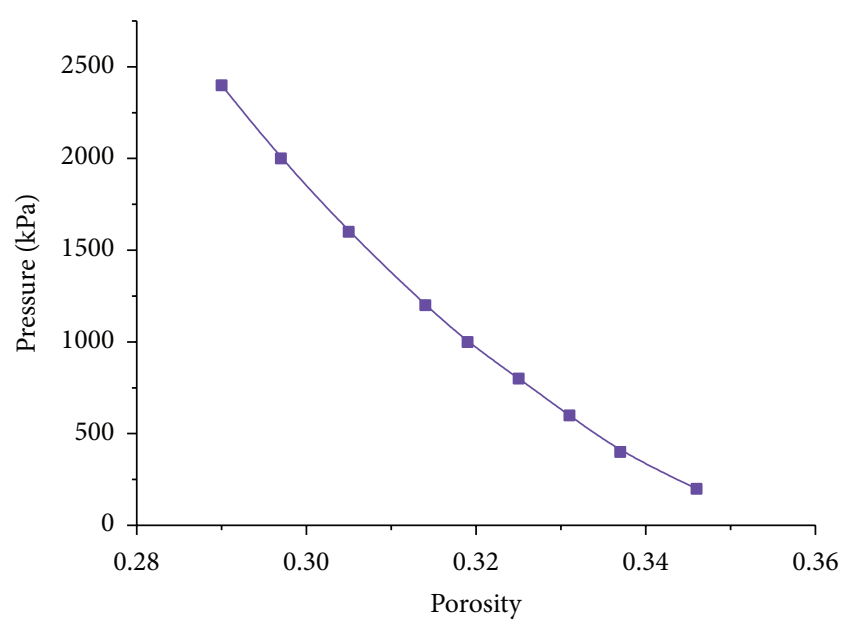

Figure 5: The $e$ - $p$ curve of soil.

TABLE 3: Constitutive parameters.

\begin{tabular}{lcccc}
\hline Density $\left(\mathrm{g} / \mathrm{cm}^{3}\right)$ & $E(\mathrm{Mpa})$ & Poisson's ratio & $C(\mathrm{MPa})$ & $\phi\left(^{\circ}\right)$ \\
\hline 1.880 & 11 & 0.26 & 0.15 & 18 \\
\hline
\end{tabular}

TABLE 4: Moisture content and dry density.

\begin{tabular}{lccccc}
\hline Moisture content $(\%)$ & 8 & 9.4 & 10.4 & 12.7 & 16.9 \\
Dry density $\left(\mathrm{g} / \mathrm{cm}^{3}\right)$ & 1.88 & 1.97 & 1.98 & 1.94 & 1.85 \\
\hline
\end{tabular}

\section{Numerical Simulation}

5.1. 3D Model Simulation. In order to analyze the degree of blasting compaction with high temperature and to optimize the holes arrangement, the 3D numerical model with a single hole was built with software FLAC3D [23], as shown in Figure 7.

In the model, the length is 14.11 ( $x$ direction), width is $14.11 \mathrm{~m}$ ( $y$ direction), and the height is $10 \mathrm{~m}$ ( $z$ direction). The blast hole diameter is $110 \mathrm{~mm}$, and the model was meshed as many as 33600 zones and 35301 grid-points. The three side lengths of the finite difference zones were $0.3 \mathrm{~m}$, and 


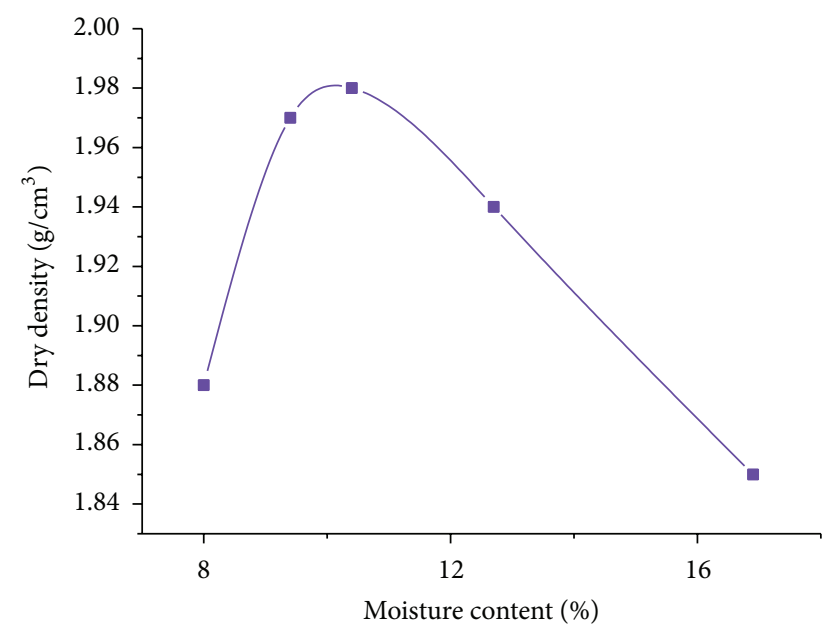

Figure 6: Moisture content and density curve.

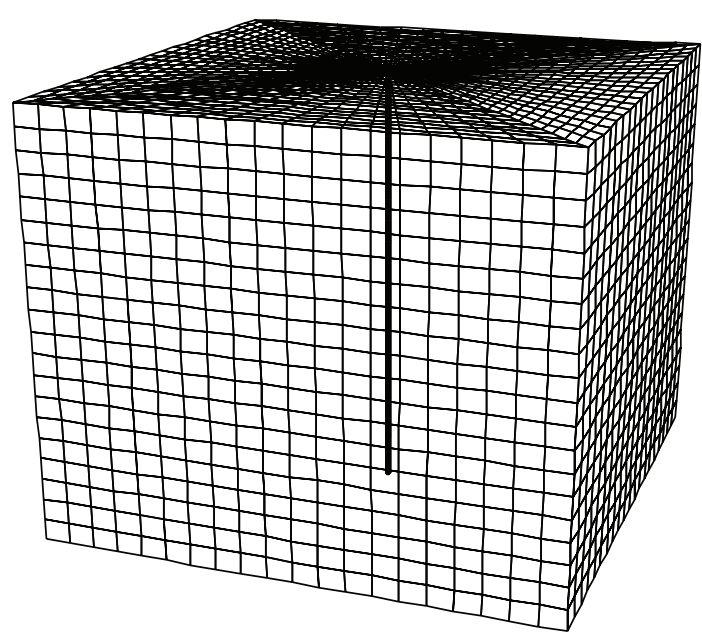

Figure 7: The 3D model in FLAC3D.

those dimensions of zones were confirmed from the model dimensions and vibration wave length.

5.2. Applied Dynamic Loading. Based on the above formula and monitored data in the field, the maximum load on the blast hole wall $P_{0}=335.5 \mathrm{Mpa}$, so the typical points on the loading curve for different stages were $P_{0}=0, P_{1}=$ $335.5 \mathrm{Mpa}, P_{2}=108.73 \mathrm{Mpa}, P_{3}=6.02 \mathrm{Mpa}$, and $P_{4}=0$, with respect to the time: $t_{0}=0 \mathrm{~s}, t_{1}=0.01 \mathrm{~s}, t_{2}=0.03 \mathrm{~s}$, $t_{3}=0.122 \mathrm{~s}$, and $t_{4}=0.132 \mathrm{~s}$. Based on the measured results compared with trial results, the damping of surrounding soil is 0.025 . For the thermal strain, the conductivity is $1.61 \mathrm{Wm}^{-1} \mathrm{k}^{-1}$ and the expansion coefficient is $1.3 \times 10^{-5}$ which were obtained from the lab tests.

5.3. Verification for the Model. In this simulation, the solving time was $1 \mathrm{~s}$ after 284638 solving steps. The predicted velocity curves compared with the monitored curves are shown in Figures 8 to 10 .

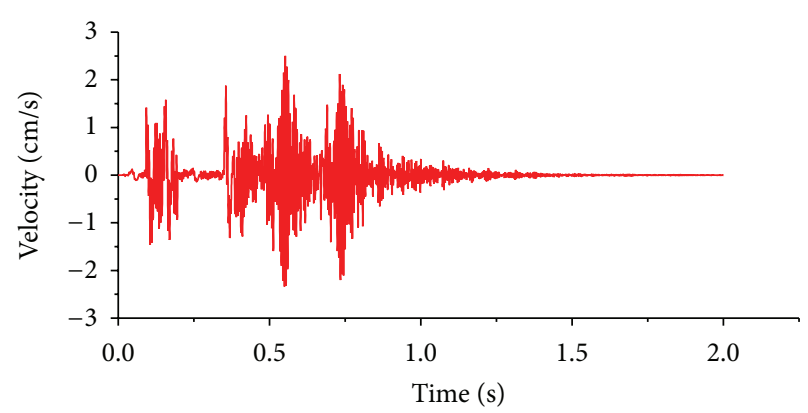

FIGURE 8: In situ velocity curve.

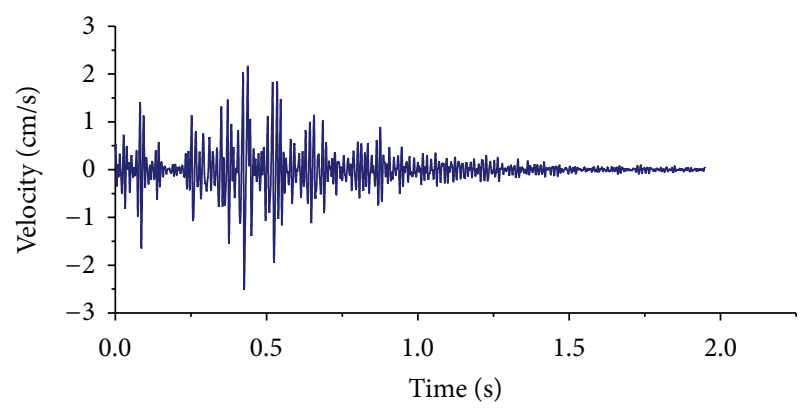

FIGURE 9: Simulated velocity curve.

TABLE 5: Field monitored and model predicted stress.

\begin{tabular}{lccc}
\hline Field test & $\begin{array}{c}2 \mathrm{~m} \text { soil pressure } \\
(\mathrm{MPa})\end{array}$ & $\begin{array}{c}4 \mathrm{~m} \text { soil pressure } \\
(\mathrm{MPa})\end{array}$ & $\begin{array}{c}6 \mathrm{~m} \text { soil pressure } \\
(\mathrm{MPa})\end{array}$ \\
\hline Number 1 & 1.34 & 0.29 & -0.0028 \\
Number 2 & 1.37 & 0.31 & 0.0029 \\
Number 3 & 1.35 & 0.26 & -0.0048 \\
Simulation & 1.33 & 0.26 & 0.003 \\
Error rate & $1.7 \%$ & $9 \%$ & $37.8 \%$ \\
\hline
\end{tabular}

As shown in Figure 8, the predicted peak velocity (PPV) value is $2.62 \mathrm{~cm} / \mathrm{s}$, and in Figure 9, the monitored peak velocity value is $2.51 \mathrm{~cm} / \mathrm{s}$. The error rate is $3 \%$. The arrival times of two curves are the same and around $0.5 \mathrm{~s}$.

In the field, there were also three series of soil pressure boxes; the monitored data are shown in Table 5 . The model predicted results are shown in Figure 10 and Table 5.

Based on the above analysis, the simulated curve and monitored curve had the same tendency. Moreover the field monitored soil pressure is the same as the model predicted value. The error rates are between $1.7 \%$ and $37.8 \%$. Thus, the model simulation is proven to be useful to predict the blasting compaction.

5.4. Thermal Analysis. Many researches have shown that the center temperature could reach $3000^{\circ} \mathrm{C}$ in geotechnical blasting, so the thermal swelling of surrounding soil could not be ignored. The temperature changed during the blasting procedure. The degree and range of thermal impacts should be predicted at first. The predicted 3D thermal contours are shown in Figure 11. 


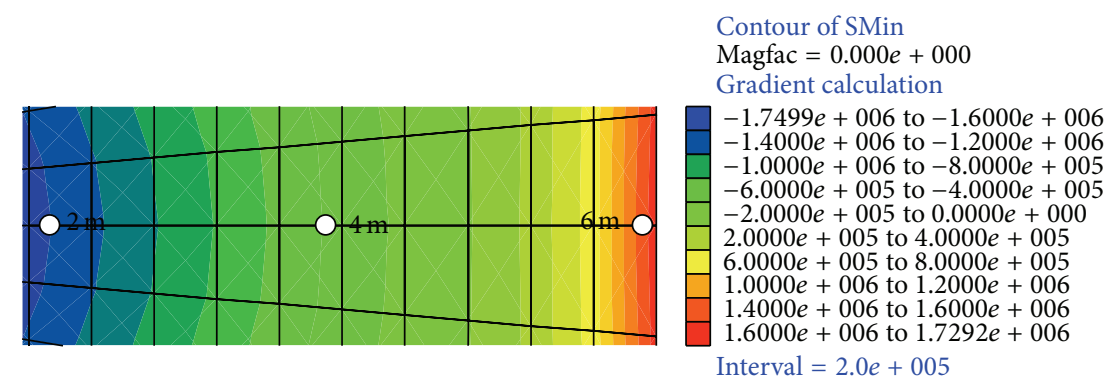

FIgURE 10: The maximum principal stress.
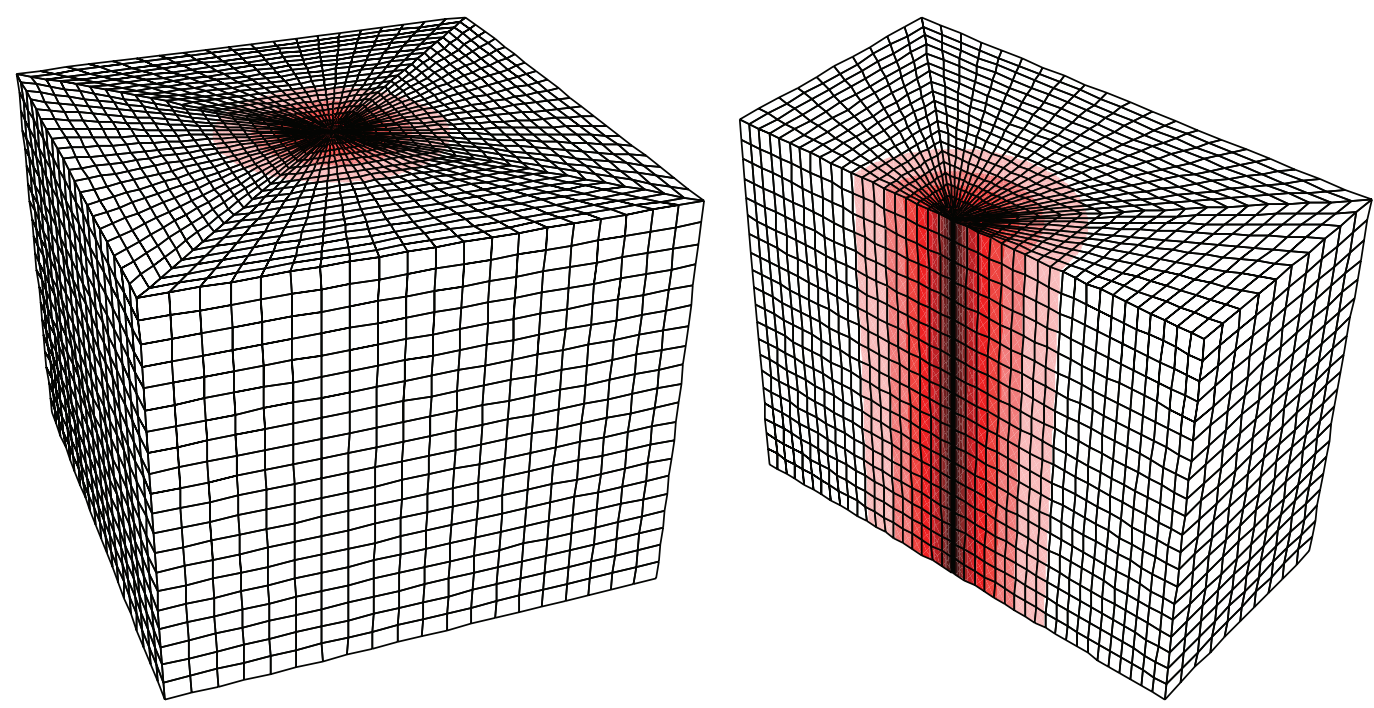

Figure 11: 3D thermal contours.

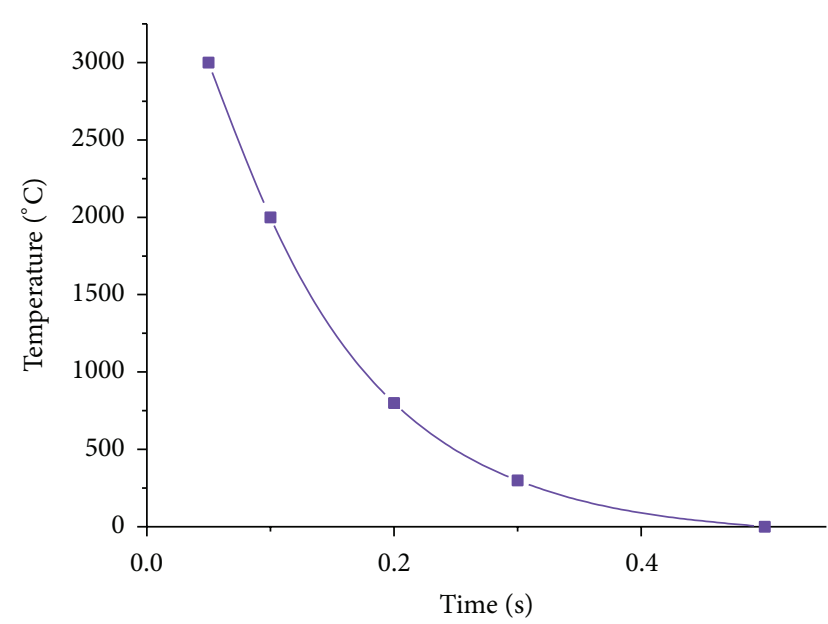

FIgURE 12: The temperature change curve.

Considering the temperature change which had the relationship with gas pressure change, the temperature of typical point of blasting can be figured out. The temperature change curve is shown in Figure 12. The typical thermal contours are drawn by intercepting the typical profile and extracting related data and shown in Figures 13, 15, and 17. After

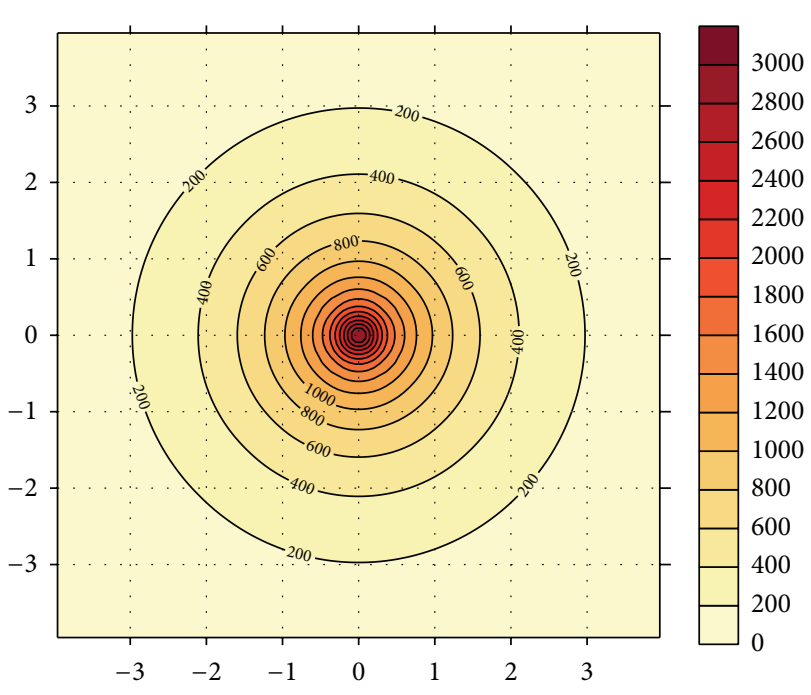

FIgURE 13: $3000^{\circ} \mathrm{C}$ thermal contours.

calculating, the thermal expansion contours are expressed in Figures 14, 16, and 18.

As shown in Figures 13 and 14, the radius of the range with temperature more than $200^{\circ} \mathrm{C}$ is $3 \mathrm{~m}$ in surrounding soil, and 

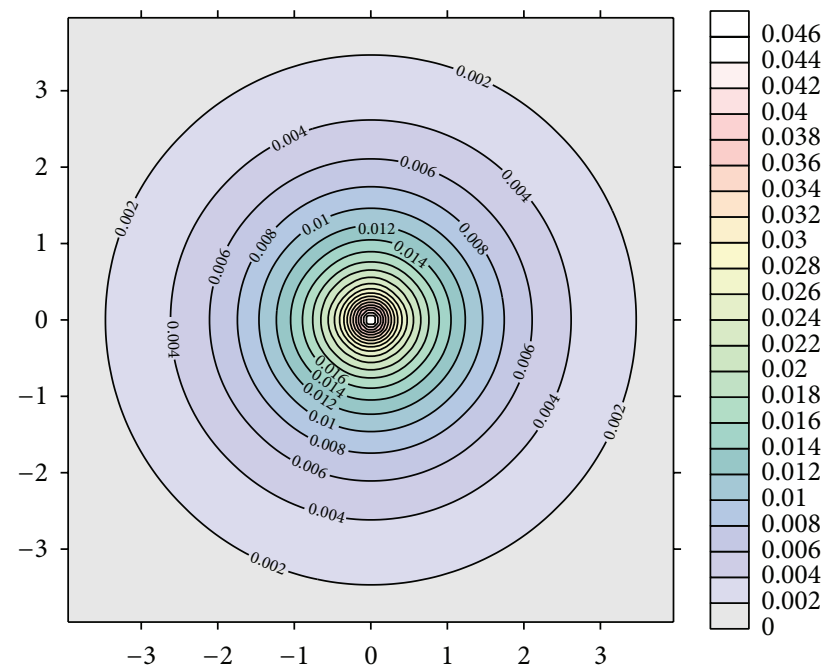

FIgURE $14: 3000^{\circ} \mathrm{C}$ thermal expansion contours.

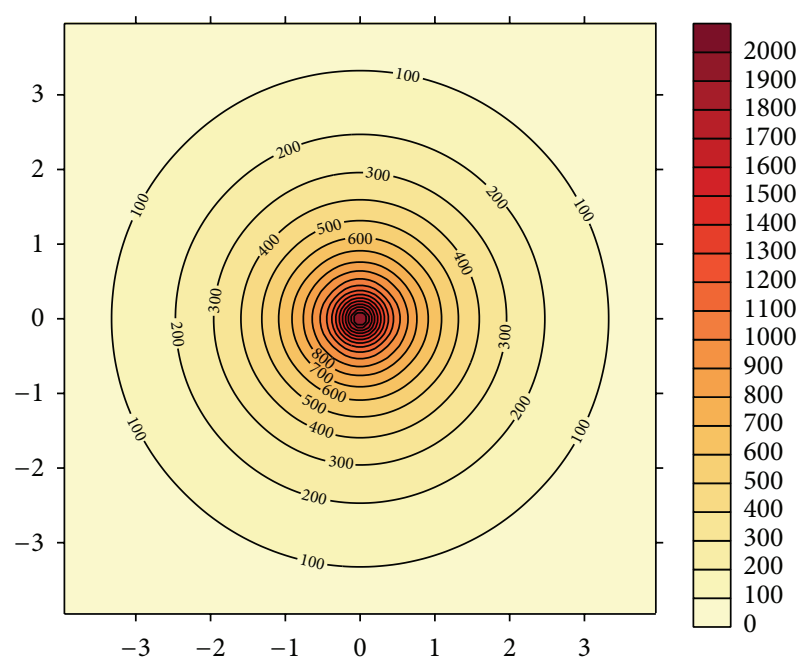

FIGURE $15: 2000^{\circ} \mathrm{C}$ thermal contours.

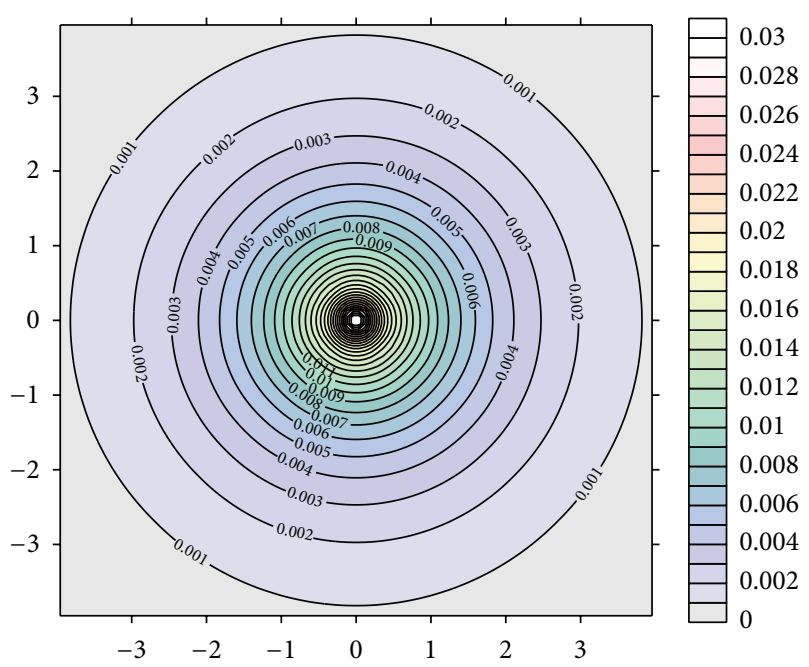

Figure 16: $2000^{\circ} \mathrm{C}$ thermal expansion contours.

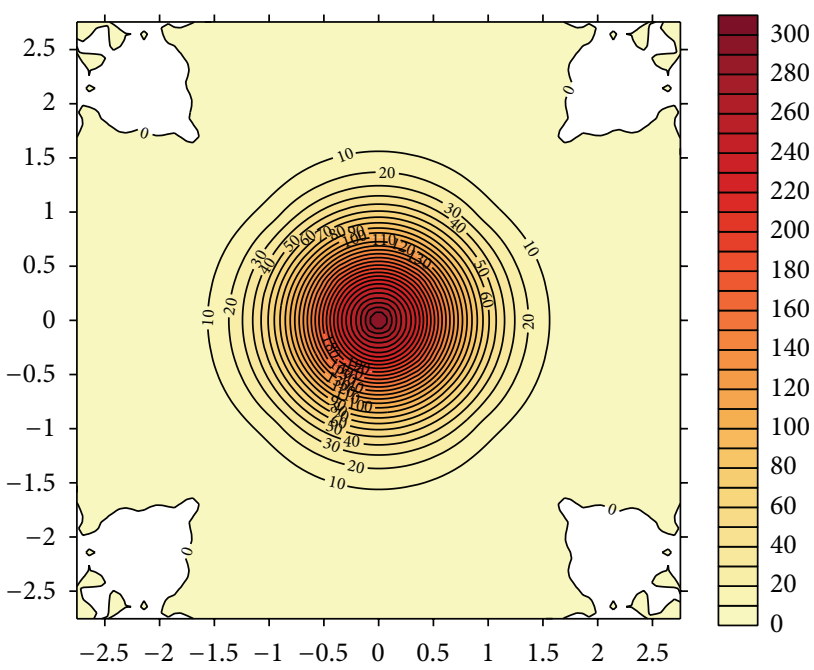

Figure $17: 300^{\circ} \mathrm{C}$ thermal contours.

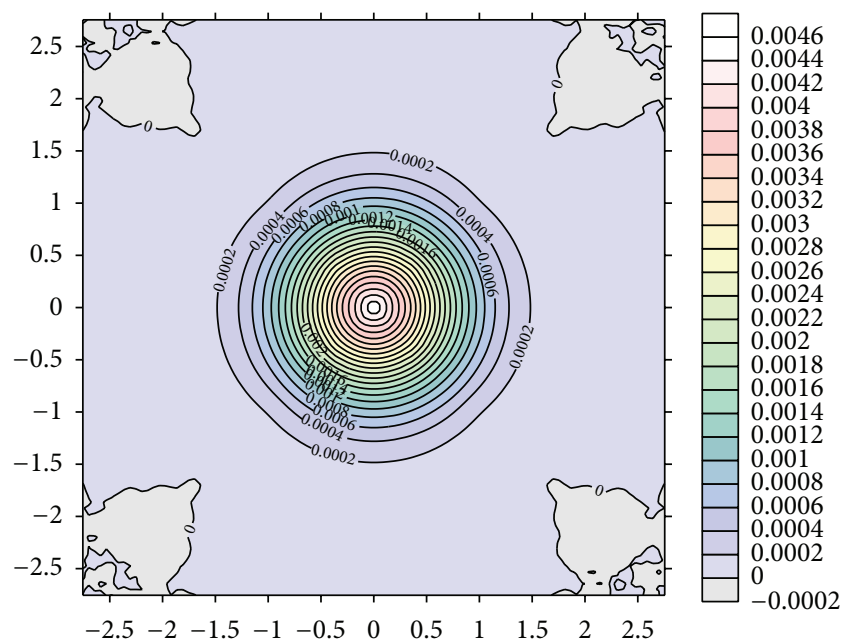

FIGURE $18: 300^{\circ} \mathrm{C}$ thermal expansion contours.

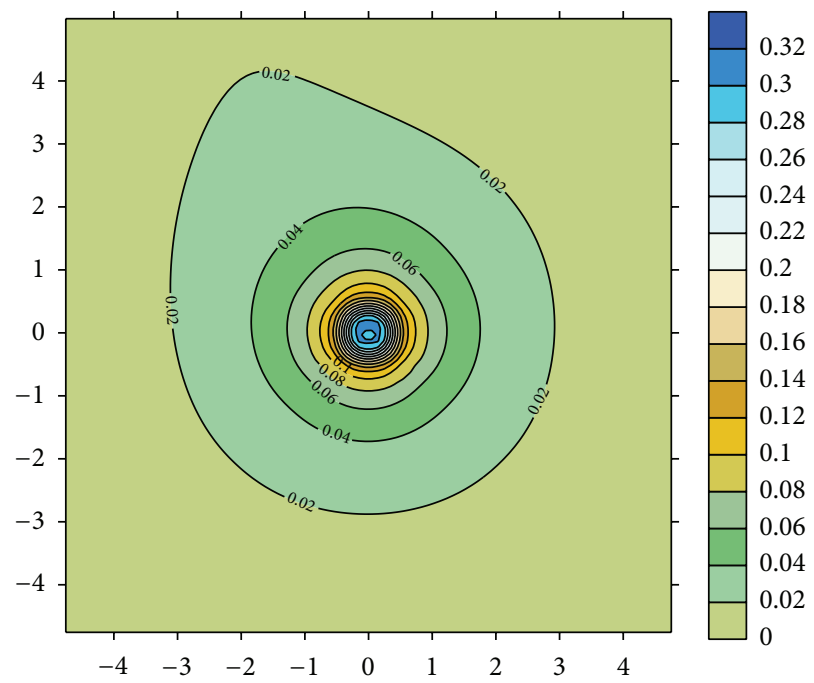

Figure 19: Profile displacement contours. 


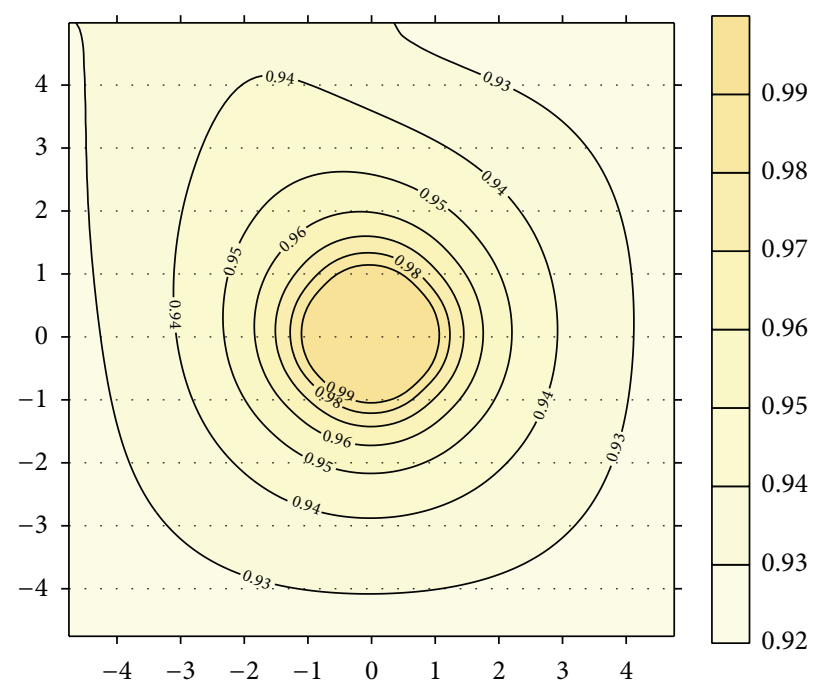

FIgure 20: Profile compaction degree and its scope.
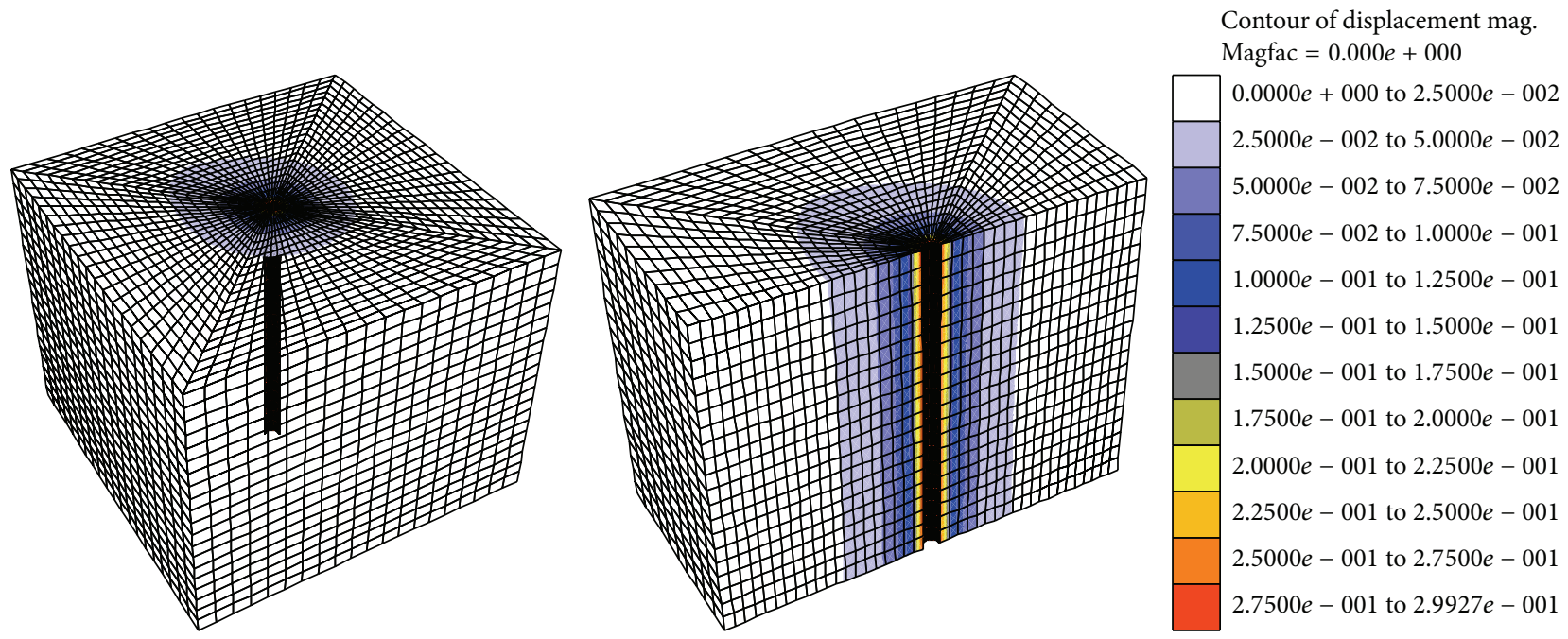

FIgURE 21: 3D maximum displacement contours.

within this range, the displacements change from $0.2 \mathrm{~cm}$ to $4.6 \mathrm{~cm}$. As shown in Figures 15 and 16, the radius of the range with temperature more than $200^{\circ} \mathrm{C}$ is $2.3 \mathrm{~m}$ in surrounding soil, and within this range, the displacements change from $0.2 \mathrm{~cm}$ to $3 \mathrm{~cm}$. As shown in Figures 17 and 18, the radius of the range with temperature more than $200^{\circ} \mathrm{C}$ is $0.5 \mathrm{~m}$ in surrounding soil, and within this scope, the displacements change from $0.2 \mathrm{~cm}$ to $0.5 \mathrm{~cm}$. These figures show that the temperature is declined along with the pressure reduction. Both of the range and degree become smaller.

Per simulation, the range and degree of blasting compaction are shown in Figure 21 which is $3 \mathrm{D}$ contours in surrounding soil. The typical contours profile is shown in Figure 19. The contours of compaction degree are shown in Figure 20.

As shown in Figures 19 to 21, the radii of the range with maximum displacement more than $2 \mathrm{~cm}$ are $3 \mathrm{~m}$ to $4 \mathrm{~m}$ in surrounding soil. The radius of the range with compaction degree more than $95 \%$ is $2.5 \mathrm{~m}$ around the blast hole, so the radius of the effect range of blasting compaction was $2.5 \mathrm{~m}$.

\section{Conclusion}

Through the analysis of the blasting pressure change, a mathematic model was built on the basis of the blast hole volume expansion, the fracture development, and the blasting gas motion in order to predict the dynamic loading curve. After verification, the improved dynamic loading curve is more close to the real loading. It could provide more reasonable prediction comparing with the existing simplified triangular load and trapezoidal load in simulation.

Due to the $3000^{\circ} \mathrm{C}$ high temperature of blasting center, the TM coupled analysis is necessary. Based on the simulation, the radius of the range with temperature more than $200^{\circ} \mathrm{C}$ is $3 \mathrm{~m}$ in surrounding soil, and within this 
range, the displacements change from $0.2 \mathrm{~cm}$ to $4.6 \mathrm{~cm}$. The temperature declines as the pressure reduces. As per the calculation, the radius of the range with compaction degree more than $95 \%$ is $2.5 \mathrm{~m}$ around the blast hole, so the impacted range of blasting compaction is $2.5 \mathrm{~m}$. This is the reason for setting the distance of two blast holes in embankment $5 \mathrm{~m}$ by taking ranks' arrangement or quincuncial arrangement.

\section{Conflict of Interests}

The authors declare that there is no conflict of interests regarding the publication of this paper.

\section{References}

[1] Q. Chen, Y. H. Zou, M. Tang, and C. R. He, "Modelling the construction of a high embankment dam," KSCE Journal of Civil Engineering, vol. 18, no. 1, pp. 93-102, 2014.

[2] G. Yang, R. Xue, and H. Li, "Application of dynamic drainage consolidation method in subgrade strengthening," Applied Mechanics and Materials, vol. 170-173, pp. 2395-2398, 2012.

[3] R. Walker and B. Indraratna, "Consolidation analysis of a stratified soil with vertical and horizontal drainage using the spectral method," Geotechnique, vol. 59, no. 5, pp. 439-449, 2009.

[4] J.-C. Chai, J. P. Carter, and S. Hayashi, "Vacuum consolidation and its combination with embankment loading," Canadian Geotechnical Journal, vol. 43, no. 10, pp. 985-996, 2006.

[5] W.-L. Zou, Z. Wang, and Z.-F. Yao, "Effect of dynamic compaction on placement of high-road embankment," Journal of Performance of Constructed Facilities, vol. 19, no. 4, pp. 316-323, 2005.

[6] S.-J. Feng, W.-H. Shui, K. Tan, L.-Y. Gao, and L.-J. He, "Field evaluation of dynamic compaction on granular deposits," Journal of Performance of Constructed Facilities, vol. 25, no. 3, pp. 241-249, 2011.

[7] H. Zhang and B. Zhang, "Study on deformation parameters in Dynamic Compaction desert foundation," Applied Mechanics and Materials, vol. 170-173, pp. 357-360, 2012.

[8] C. Chen, "Effect of dynamic compaction on red sand soil filling embankment," Applied Mechanics and Materials, vol. 268-270, no. 1, pp. 788-791, 2013.

[9] Z.-F. Xia, G.-L. Ye, J.-H. Wang, B. Ye, and F. Zhang, "Fully coupled numerical analysis of repeated shake-consolidation process of earth embankment on liquefiable foundation," Soil Dynamics and Earthquake Engineering, vol. 30, no. 11, pp. 13091318, 2010.

[10] H. M. Abuel-Naga, D. T. Bergado, and S. Chaiprakaikeow, "Innovative thermal technique for enhancing the performance of prefabricated vertical drain during the preloading process," Geotextiles and Geomembranes, vol. 24, no. 6, pp. 359-370, 2006.

[11] R. K. Rowe and C. Taechakumthorn, "Combined effect of PVDs and reinforcement on embankments over rate-sensitive soils," Geotextiles and Geomembranes, vol. 26, no. 3, pp. 239-249, 2008.

[12] A. K. Sinha, V. G. Havanagi, and S. Mathur, "An approach to shorten the construction period of high embankment on soft soil improved with PVD," Geotextiles and Geomembranes, vol. 27, no. 6, pp. 488-492, 2009.

[13] B. Indraratna, A. Aljorany, and C. Rujikiatkamjorn, "Analytical and numerical modeling of consolidation by vertical drain beneath a circular embankment," International Journal of Geomechanics, vol. 8, no. 3, pp. 199-206, 2008.

[14] S. W. Abusharar, J.-J. Zheng, and B.-G. Chen, "Finite element modeling of the consolidation behavior of multi-column supported road embankment," Computers and Geotechnics, vol. 36, no. 4, pp. 676-685, 2009.

[15] A. Yildiz, "Numerical analyses of embankments on PVD improved soft clays," Advances in Engineering Software, vol. 40, no. 10, pp. 1047-1055, 2009.

[16] W. Li, Q. Gu, L. Su, and B. Yang, "Finite element analysis of dynamic compaction in soft foundation," Procedia Engineering, vol. 12, pp. 224-228, 2011.

[17] B. Yuan, R. Chen, J. Teng, T. Peng, and Z. Feng, "Effect of passive pile on $3 \mathrm{D}$ ground deformation and on active pile response," The Scientific World Journal, vol. 2014, Article ID 904186, 6 pages, 2014.

[18] J. Henrych, The Dynamics of Explosion and its Use, Elsevier Scientific, New York, NY, USA, 1979.

[19] L. Lee, C. Homing, and J. Kury, "The charge transport problems," Lawrence Livermore Laboratory Report UCRL50442[R], [S. 1.]:[s.n], 1986.

[20] R. W. Lewis and B. A. Schrefler, The Finite Element Method in Deformation and Consolidation of Porous Media, Wiley, New York, NY, USA, 1987.

[21] M. Fall and O. Nasir, "Numerical modeling of gas migration from a DGR in ontarios sedimentary rocks," Tech. Rep., CNSC, Ottawa, Canada, 2012.

[22] V. Navarro and E. E. Alonso, "Modeling swelling soils for disposal barriers," Computers and Geotechnics, vol. 27, no. 1, pp. 19-43, 2000.

[23] Itasca Consulting Group, FLAC3D V4.0, Fast Lagrangian Analysis of Continua in 3 Dimensions, User's Guide, Itasca Consulting Group, Minneapolis, Minn, USA, 2009. 

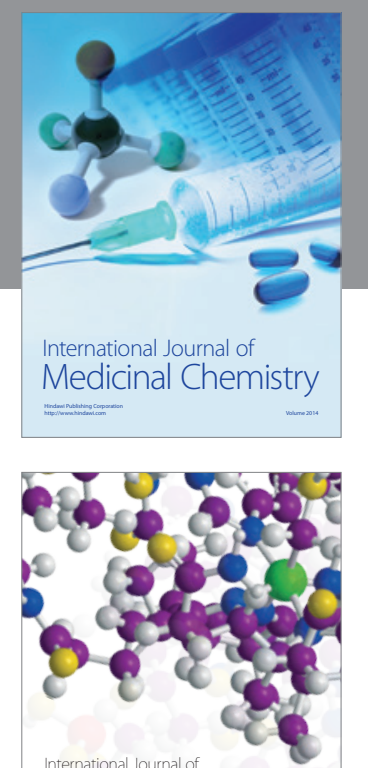

\section{Carbohydrate} Chemistry

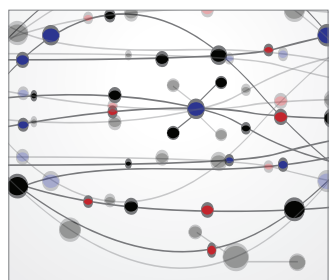

The Scientific World Journal
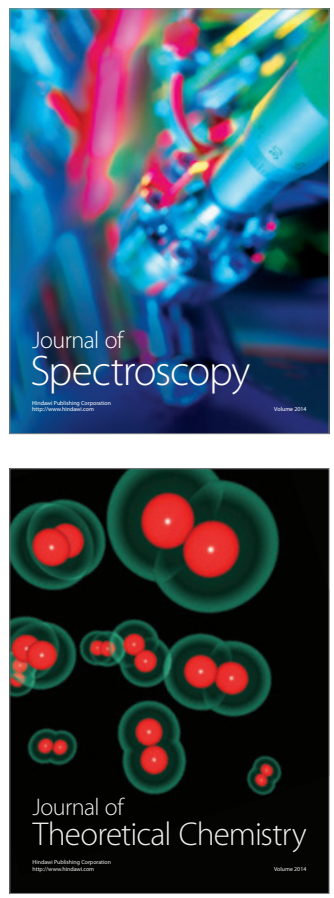
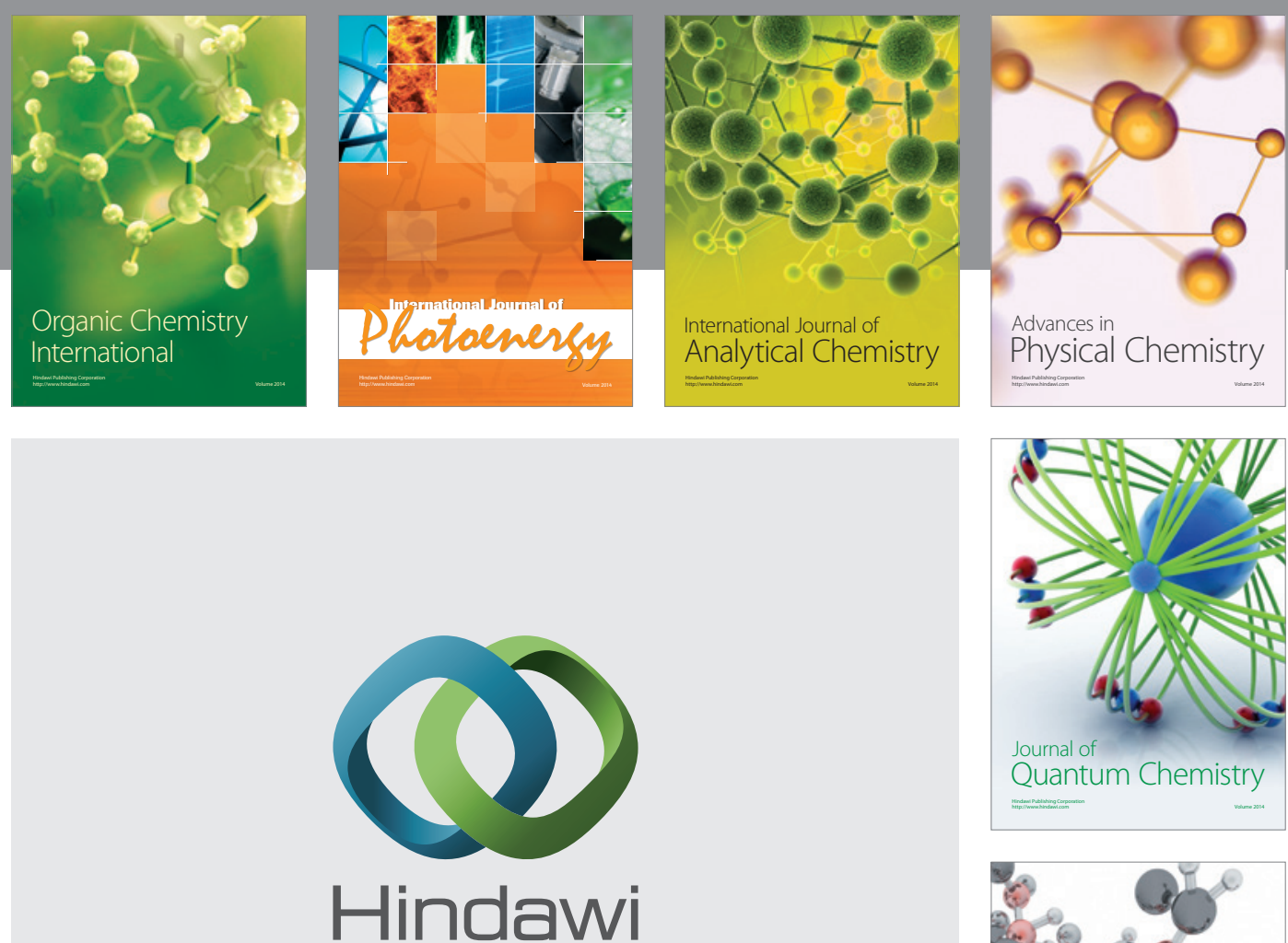

Submit your manuscripts at

http://www.hindawi.com

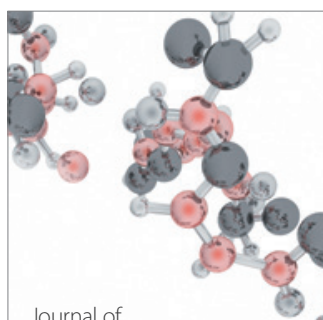

Analytical Methods

in Chemistry

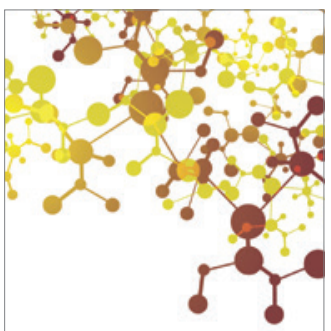

Journal of

Applied Chemistry

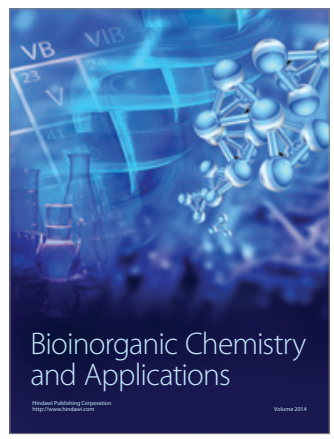

Inorganic Chemistry
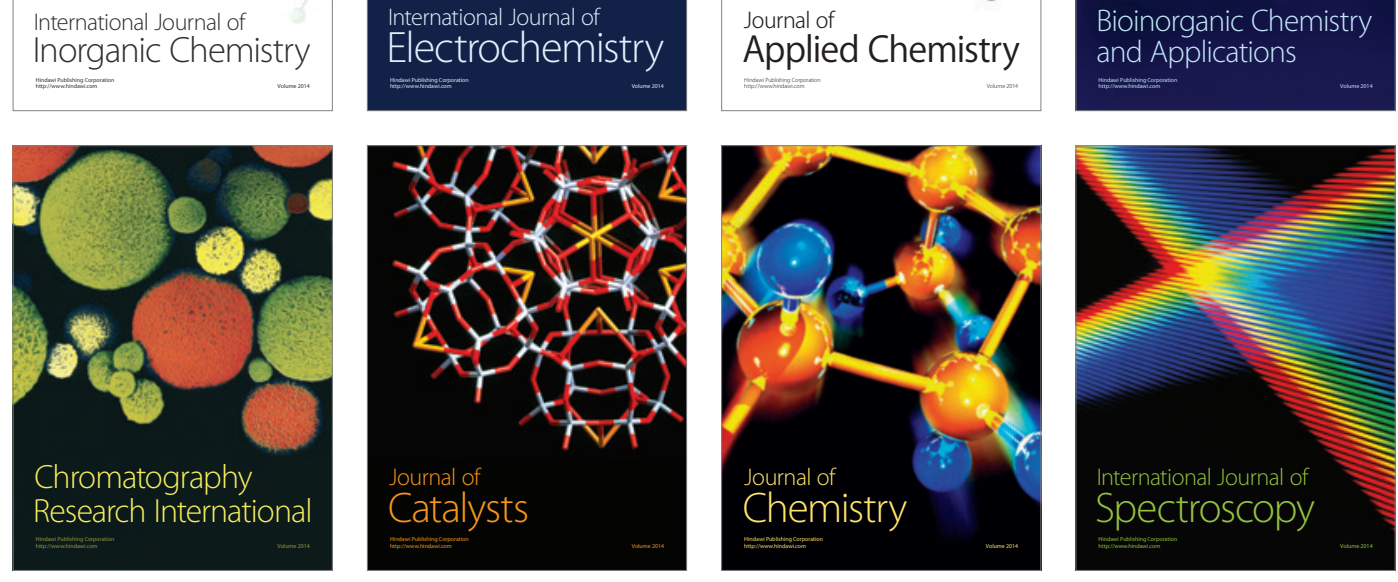